\title{
MODELLING FLUID FLOW IN STRESS SENSITIVE PETROLEUM RESERVOIR CONSIDERING FAULT REACTIVATION PROBLEM
}

\author{
I. F. Gomes ${ }^{1}$, L. J. N. Guimarães ${ }^{2}$, I. D. S. Pontes ${ }^{2}$, L. M. Costa ${ }^{1}$ \\ ${ }^{1}$ Department of Technology, Federal University of Pernambuco (gomes@ufpe.br) \\ ${ }^{2}$ Department of Civil Engineering, Federal University of Pernambuco
}

\begin{abstract}
This paper presents the application, to a synthetic example, of a formulation implemented in a finite element code CODE_BRIGHT to simulate fluid flow in petroleum reservoir sensitive to stress state. In this program the equations of fluid flow problem are solved together with the stress equilibrium equation, which characterize the geomechanical problem. It's a hydro-geomechanical coupling solved in a totally implicit manner, where changes in pressure field induce changes in stress state of rocks of the field, which can lead to reactivation of sealed geological faults. The fault reactivation problem considers that shear (with dilatancy), tension or compression of filling material may cause changes in hydraulic properties. The mechanical constitutive model adopted to represent the behavior of the filling material of the fault is an elastoplastic Mohr-Coulomb model that is able to reproduce the fault activation through reservoir and adjacent rocks (fluid and pressure propagation).
\end{abstract}

Keywords: geomechanics, hydro-mechanical coupling, finite elements.

\section{INTRODUCTION}

Fault is defined as being a fracture surface, along which has occurred a relative displacement between two rock blocks, and it can be originated from an extension, distension or torsion. The sealing has great significance on the creation of hydrocarbons traps, because the sealing rock has low permeability and it prevents the leakage of fluid from the rock reservoir.

The motion of faults within and on the surrounds of a petroleum reservoir can be induced in an exploitation process, by reducing the pore pressure and its effect over the normal effective stress and shear failure, and it is also a direct function of the stress state that acts on the field and on the fault surfaces. When the reactivation occurs, the permeability of the fault is increased, allowing the fluid to flow through it, compromising the hydraulic integrity of the cap rocks that seal the reservoir. Another aspect due to the fault reactivation is the opening of fractures and the appearance of new flow zones through cap formations of high capillarity and low permeability.

This reveals the need of an accurate prediction of the fluid's injection/production effect over the mechanical behavior of the rocks and the fault, as well as the influence of the reactivated fault over the hydrocarbons flow regimen inside the reservoir. Many researches involving hydro-mechanical numerical modeling of fault reactivation problems are being developed such in [1], [2], [3], [4] and [5], among others. 
This paper presents a coupled hydro-mechanical numerical analysis of fault reactivation in petroleum reservoirs to verify the influence of the fluid`s injection and production over the reactivation. For that, it will be used the "in house" code in finite elements CODE_BRIGHT (COupled DEformation, BRIne, Gas and Heat Transport) presented by [6], in which in the mechanical coupling, the hydraulic problem equations are solved together with the stress equilibrium equation, that features the geomechanical problem, here being considered the mechanical constitutive model from Mohr Coulomb for fault material.

\section{MATHEMATICAL FORMULATION}

In the adopted formulation, the geomechanical problem has the stress-strain behavior of the rock relative to the acting stresses and the pressure and saturation fields of the fluids. In the flow problem, the permeability and porosity of the rock are updated in each time interval. It is proposed here to solve, considering small deformations and constant temperature, mass and momentum balance equations for each phase, where the mechanical problem is defined by the stress equilibrium equation, showed bellow, considering constitutive laws and complementary equations, and the hydraulic problem is characterized by the mass balance equation of the fluid phase using Darcy`s Law.

$$
\nabla \boldsymbol{\sigma}+\mathbf{b}=0
$$

Where $\boldsymbol{\sigma}$ is the total stress tensor and $b$ is the volumetric vector of the body forces. The mass balance of phase is represented by:

$$
\frac{D^{s}\left(\rho^{\alpha} \phi S_{v}^{\alpha}\right)}{D t}+\nabla\left(\rho^{\alpha} \mathbf{q}_{v}^{\alpha}\right)+\rho^{\alpha} \phi S^{\alpha} \nabla \dot{\mathbf{u}}+f^{\alpha}=0
$$

Where $D^{S} / D t$ is the derivative of time concerning the solid phase, $\rho^{\alpha}$ is the density of the phase, $\phi$ is the porosity, $S_{v}^{\alpha}$ the volume of phase $\alpha$ over the volume of all the fluid phases (here its vale equals 1 assuming a single-phase fluid flow), $\mathbf{q}_{v}^{\alpha}$ is the Darcy`s flow of phase $\alpha$, e $f_{\alpha}$ a source/sink mass term of phase $\alpha$. The invariants of the problem are the nodal displacement vector $\mathrm{u}$, the nodal pressure of liquid $p^{\alpha}$ (in this article, only water is considered inside the pores). All of the others variables $\phi, \rho^{\alpha}, S_{v}^{\alpha}$ and $\mathbf{q}_{v}^{\alpha}$ are listed as unknowns through the constitutive relations. The purpose of this article is to employ a special attention to the mechanical and hydraulic constitutive equations that will be discussed further ahead. The main constitutive equation for the hydraulic problem is the Darcy's law:

$$
\mathbf{q}_{v}^{\alpha}=\frac{\mathbf{K}_{i} k_{r}^{\alpha}}{\mu^{\alpha}}\left(\nabla p^{\alpha}+\rho^{\alpha} \mathbf{g}\right)
$$

where $\mathbf{K}_{\mathrm{i}}$ is the permeability tensor, $k_{r \alpha}$ is the relative permeability of the phase (here its equals 1), which is a function of the phase saturation level, and $\mu_{\alpha}$ is the viscosity of the phase. 


\subsection{Geomechanical constitutive model}

The model used was the Mohr-Coulomb viscoplastic model. In this model, the stress and deformation increases are listed by:

$$
d \boldsymbol{\sigma}^{\prime}=\mathbf{D}^{e p} d \boldsymbol{\varepsilon}
$$

Where $d \boldsymbol{\sigma}$ is the effective stress increment, $\mathbf{D}^{e p}$ is the elastoplastic constitutive tensor and $d \boldsymbol{\varepsilon}$ is the deformation increment. The stresses tensor is determined by the effective stress principle:

$$
d \boldsymbol{\sigma}^{\prime}=d \boldsymbol{\sigma}+\mathbf{m} d P_{\alpha}
$$

Where $d \boldsymbol{\sigma}$ is the increment of the total stress and $\mathbf{m}$ is an auxiliary tensor, in which the values of the normal components is 1 and the shear components is zero.

The set of equations for the yield function and Mohr-Coulomb are presented next:

$$
\begin{gathered}
F(\boldsymbol{\sigma}, \mathbf{h})=J-\left(\frac{c^{\prime}}{\tan \varphi^{\prime}}+p^{\prime}\right) G(\theta)=0 \\
G(\theta)=\frac{\operatorname{sen} \varphi^{\prime}}{\cos \theta+\sin \theta \sin \varphi^{\prime}}
\end{gathered}
$$

Where $F(\boldsymbol{\sigma}, \mathbf{h})$ is the function that features the Mohr-Coulomb failure criteria. $J$ is the deviatoric stress, $p^{\prime}$ is the mean effective stress, $c^{\prime}$ is the effective coesion, $\varphi^{\prime}$ is the effective shear angle and $\theta$ is the Lode's angle. It's considered the Perzyna's model in which the viscoplastic parameter is applied to the flow rule of elastoplastic model.

\subsection{Hydro-geomechanical coupling}

An important characteristic of the used formulation is the coupling between the variation of the porosity and the changes on the intrinsic permeability. The variation of the porosity is computed using the solid's balance equation, given by:

$$
\frac{D \phi}{D t}=\frac{(1-\phi)}{\rho^{s}} \frac{D \rho^{s}}{D t}+(1-\phi) \dot{\varepsilon}_{v}
$$

Where $\varepsilon_{v}$ is the volumetric deformation.

The determination of the permeability as a rock deformation function is a complex function which depends on the elastic or inelastic regimen to which the material is subjected. For the Mohr-Coulomb elastoplastic model it is used a linear law, limiting the value of the permeability as a shear plastic deformation function, which is directly related to the volumetric plastic deformation to a given dilatancy angle. 


\section{RESULTS AND DISCUSSION}

One example of application is presented here through a hydro-mechanical analysis of a petroleum reservoir sectioned by a fault with a single filling material. The analysis considers the plane deformation for numerical modeling for the Mohr-Coulomb constitutive model.

In this case it was considered an injector well operating at a bottom hole pressure (BHP) of 4.0 $\mathrm{MPa}$ and a producing well of $-4.0 \mathrm{MPa}$. The problem scheme and the finite element mesh are showed as following.

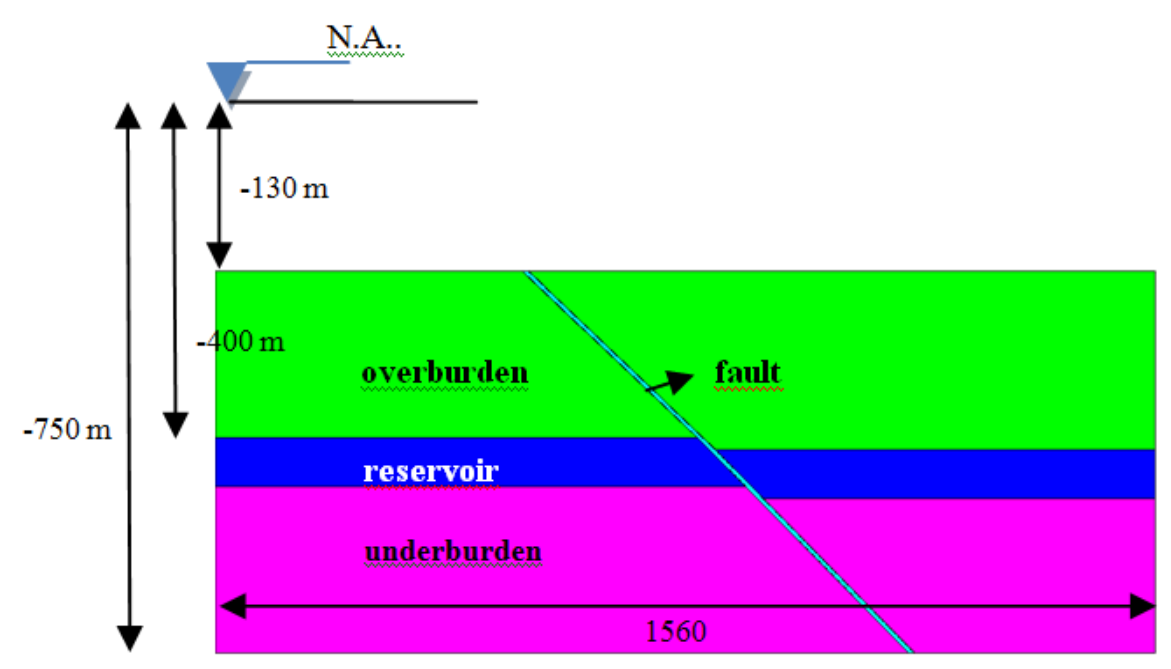

(a)

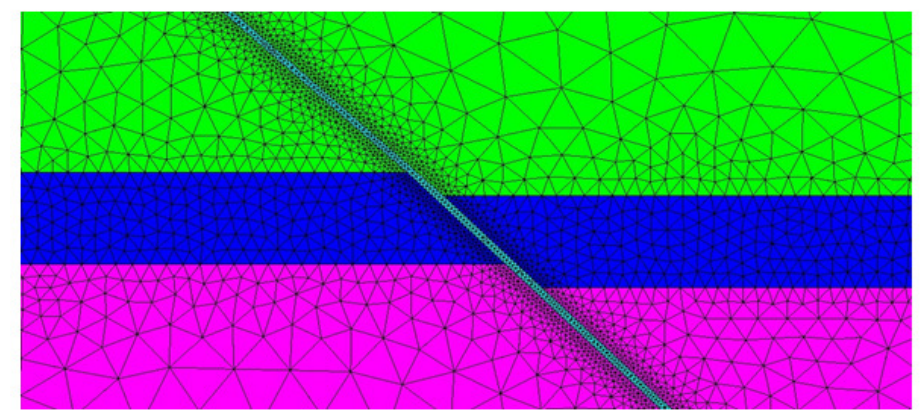

(b)

Figure 1. Description of the synthetic problem: (a) geometry of the case with simple fault. (b) finite element mesh for the simple fault case.

The finite element mesh is composed of 4191 nodes and 8266 elements. The compressibility and the density of the fluid are, respectively $1.0 \times 10^{-4} 1 / \mathrm{MPa}$ e $1001.7 \mathrm{~kg} / \mathrm{m}^{3}$. The properties of the materials adopted for the analysis are shown on following table.

Table 1 - Properties of the rock.

\begin{tabular}{l|l|l|l|l}
\hline \multicolumn{1}{c|}{ Properties of the Rock } & Overburden & Underburden & Reservoir & Fault \\
\hline Young's Module $E(\mathrm{MPa})$ & 6780 & 10800 & 15860 & 8000 \\
\hline Coesion $c(\mathrm{MPa})$ & 2.30 & 2.30 & 5.80 & 0.80 \\
\hline Shear Angle $\varphi\left(^{\circ}\right)$ & $26^{\circ}$ & $26^{\circ}$ & $30^{\circ}$ & $23.0^{\circ}$ \\
\hline Permeability $k\left(\mathrm{~m}^{2}\right)$ & $1 \times 10^{-30}$ & $1 \times 10^{-30}$ & $5 \times 10^{-12}$ & $5 \times 10^{-22}$ \\
\hline Porosity $\phi$ & 0.20 & 0.18 & 0.30 & 0.25 \\
\hline
\end{tabular}


The pressure field is changed in the interior of the reservoir due to the influence of the injector and producing wells, modifying therefore, the stress state, leading to the concentration of the shear stress on the structure of the fault.

These changes in the stresses state and in the pressure field and the shear stress in the fault lead to development of shear plastic strains, showed in Figure 2, which cause the reactivation of the fault through the increase of its permeability (Figure 3), for the maximum value equal to reservoir permeability. It is observed that the plastic strains are developed on the zone of shear stresses concentration, leading to an increase on the permeability of the element in contact with the reservoir on the right (with producing well).

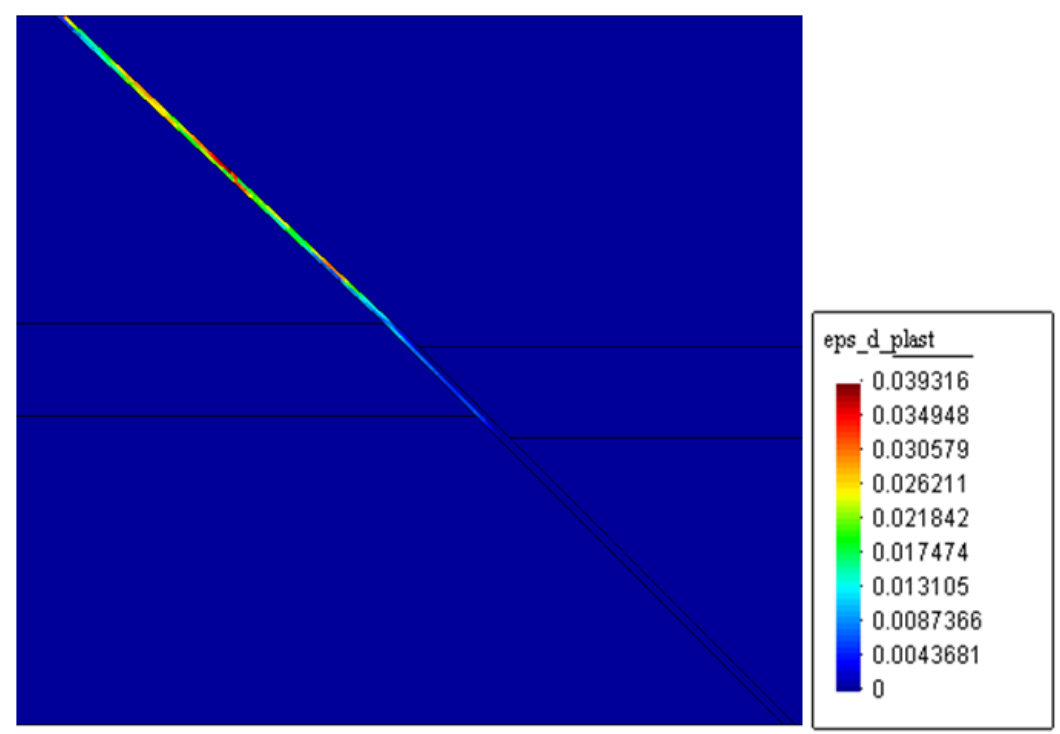

Figure 2. Distribution of shear plastic strain for final time.

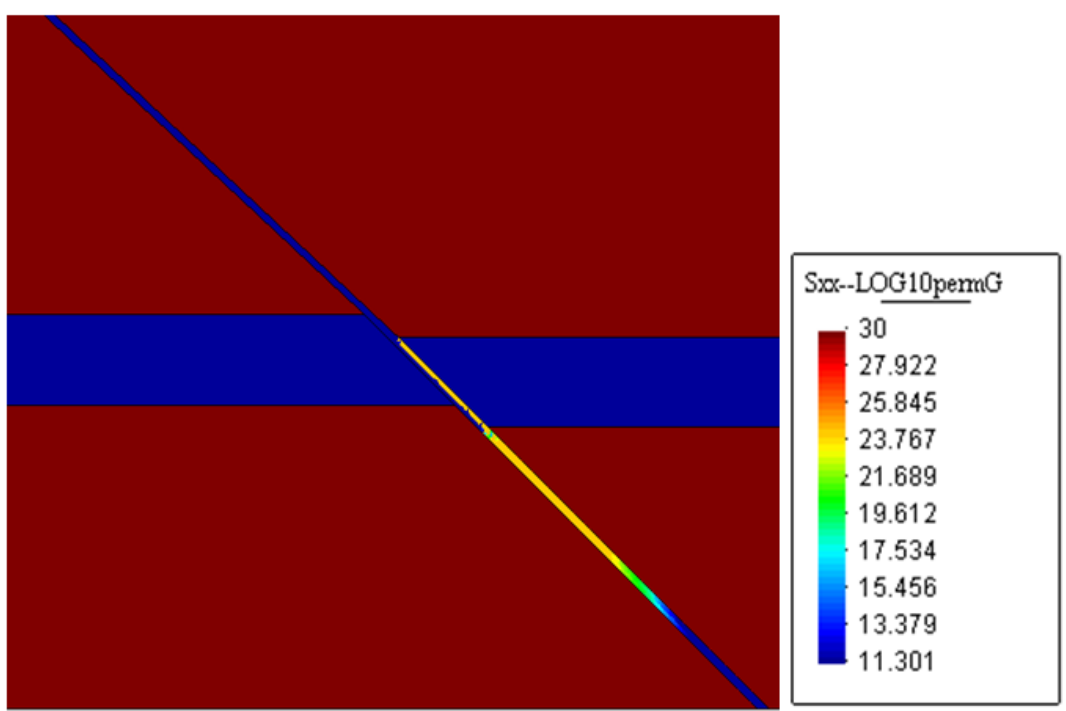

Figure 3. (-Log) Permeability distribution for final time.

This behavior implies in the communication of the reservoirs, where the injector well starts to pressurize the part of the reservoir initially compartmentalized by the sealing fault, and fluid flow occurs essentially towards the surface of the bottom of the sea, leading to the 
problem of oil exudation as showed in fluid flow vectors distribution.

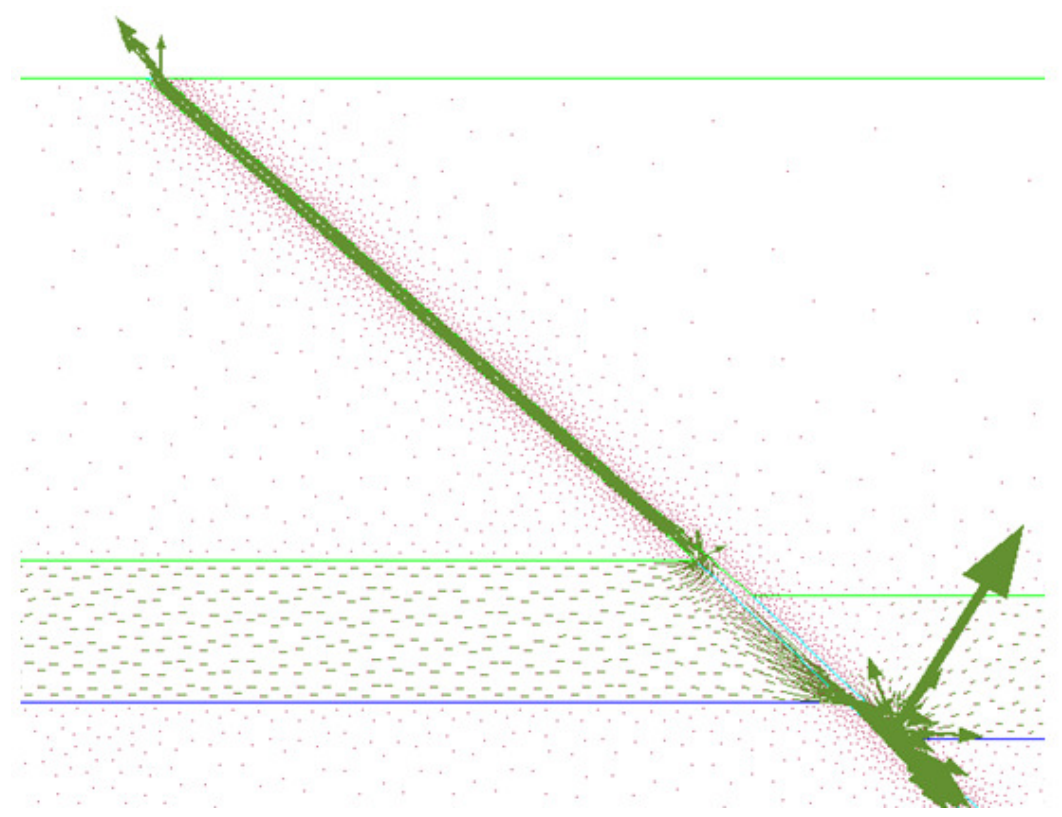

Figure 4. Fluid flow vectors distribution for final time.

\section{CONCLUSIONS}

The process of fault reactivation is characterized by the increase on the permeability of the fault filling material as a consequence of its plastification. The reactivation can interfere in the production of hydrocarbons by the lost of pressure and fluid through the fault and consequent exudation on the surface of the bottom of the sea, being essential the realization of a hydro-mechanical coupled analysis. It is observed that the increase of permeability as function of shear plastic strains, occurs element to element, with sequential effect. This problem will depend of stiffness and shear strength of each zone, as well as of other properties. The plastification criteria of Mohr-Coulomb here used has shown results that represent the fault reactivation mechanism.

\section{Acknowledgements}

The authors thank the financial support for this research given by CNPq, by FACEPE, by the PRH-26/ANP and Petrobras.

\section{REFERENCES}

[1] Guimarães L. J. N., I. F. Gomes, J. P. V. Fernandes 2009. Influence Of Mechanical Constitutive Model On The Coupled Hydro-Geomechanical Analysis Of Fault Reactivation. 2009 SPE Reservoir Simulation Symposium. SPE 119168. The Woodlands, Texas, U.S.A. 
[2] Gomes, I. F. 2009. "Implementação Em Elementos Finitos Das Equações De Pressão E Saturação Para Problemas De Fluxo Bifásico Em Reservatorios De Petróleo Deformaveis. Universidade Federal de Pernambuco. Departamento de Engenharaia Civil. Recife. Brasil.

[3] Rutqvist, J., Birkholzer, J., Cappa, F. \& Tsang, C. -F., 2007. Estimating maximum sustainable injection pressure during geological sequestration of $\mathrm{CO}_{2}$ using coupled fluid flow and geomechanical fault-slip analysis. Energy Conversion and Management, 48, (March). pp. 1798-1807.

[4] Soltanzadeh, H., Hawkes, C. D., 2008. Semi-analytical models for stress change and fault reactivation induced by reservoir production and injection. Journal of Petroleum Science and Engineering, 60, (May). pp. 71-85.

[5] Guimarães L. J. N., Gomes I. F., Barbosa, J. A., Almeida, R. P. M. (2010). Numerical modelling of $\mathrm{CO} 2$ flow through deformable aquifers with the possibility of fault reactivation. Sixth International Congress on Environmental Geotechnics. New Delhi, India.

[6] Olivella, S., J. Carrera, A. Gens \& E. E. Alonso. 1994. Nonisothermal Multiphase Flow Of Brine And Gas Through Saline Media. Transport in Porous Media, 15, 271-293. 